\title{
Perceptual learning and the discrimination of wines'
}

\author{
RICHARD D. WALK \\ GEORGE WASHINGTON UNIVERSITY
}

Ss were required to judge whether two successive tastes of wine were the same or different. Following a pretest with no knowledge of results, Ss were divided into three groups for further training. Group I received information on correctness of the judgment and learned an identification number for each of the five wines, Group II received only knowledge whether judgments were correct, and Group III received no information. The posttest, like the pretest, gave no knowledge of results. Ss improved significantly on the posttest compared to the pretest, but training condition had no significant effect. The major improvement was in correctly judging that two wine samples were the same.

The discrimination of wines by taste is often cited as an example of perceptual learning (see Gibson, 1953; Gibson \& Gibson, 1955). William James asserted as an example of improvement in discrimination with practice that, "one man will distinguish by taste between the upper and the lower half of a bottle of old Madeira" (James, 1890, I, 509). Yet, psychologists have seldom studied wine discrimination as a topic of academic interest. James Gibson and I, about 1957, through a liberal donation of dry white New York State wines from the Widmer Co., found that college students could learn to distinguish wines by taste, i.e., could learn to attach the correct name to a sip of wine. That study was a precursor of the present one.

To demonstrate perceptual learning one must first show that some of these wines are not initially well discriminated and that improvement comes with practice. A pretest where $S$ is given no information and simply judges if two successive sips are the same or different should be less accurate than a posttest. This experiment gave three types of training between the pretest and the posttest. One group ("identification") was told if two successive sips were the same or different and was also given a name (a cardinal number) to attach to each of the five wines. A second group ("reinforcement") was told only if the S-D judgments were correct or not. A third group ("no information") was given the same set of comparisons, but it was never told if the judgments were correct.

This experiment, then, should determine whether perceptual learning occurs with various types of experience in tasting wines. There may be evidence as to which type of training is most beneficial.

\section{Method}

Five dry white New York State wines were used as sources of stimulation. They were all varietal wines (not blended). The names were Catawba, Delaware, Diana, Niagara and Missouri Riesling. The differences between them were quite genuine and could be detected by experts, but were subtle, and were unfamiliar to the average college student. Wine glasses were provided, two glasses for each wine, and each was identified for $E$ by number (from 1 to 5 ). Ss were blindfolded and handed one glass of wine followed by another. $\mathrm{S}$ was asked to judge whether the second glass of wine was the same wine or a different wine from the first. Ss were only allowed one "taste" or "sip" at a time. They did not have to swallow the wine if they did not wish to, and water was available to rinse out the mouth.

The procedure for each $S$ involved 40 judgments or 80 different sips. The first 10 judgments were the pretest. Ss were not informed of the accuracy of their judgments. The middle 20 judgments were "training" and the last 10 judgments were the posttest, without information.

The middle 20 trials of training were as follows: Group I was told if each judgment was correct and also was told an identification number for both wines. Group I Ss, following the S-D judgment, were also asked to identify the wines by number and told the number if they were incorrect. Group II received only information as to whether the S-D judgment was correct. Group III had a training condition like the pretest or posttest with no information given by $\mathbf{E}$; they had only the opportunity for comparison. Ten Ss were in each group.

In addition, during the pretest and posttest Ss rated the second wine of a pair on certain adjective dimensions, and additional tasting was permitted for the rating process. The results are not presented here.

During each phase of the experiment half of each series of presentations involved same pairs and half of the presentation involved different pairs. The wine pairs and the order of $S-D$ presentations were all randomized, but each $S$ received each of the five wines as same and as different pairs. Group I Ss had the number correspond to different wines to balance out any possible bias.

\section{Results}

Table 1 shows the average errors for each group at each stage of training. Statistical analysis was performed on the pretest as compared with the posttest. The analysis of variance is a 3 by 2 by 2 repeated measure design based on 3 training groups, 2 judgments (same or different) and 2 tests (pretest and posttest). Other statistical tests supplemented the main analysis.

Was there perceptual learning? Overall correct responses increased from $62 \%$ on the pretest to $71 \%$ on the posttest. The analysis of variance showed a significant change toward increased accuracy $(F=4.95$, df $=1 / 27, p<.05$ ) 。

Did training condition make any difference? No difference was shown by training condition $(F=0.40$, $\mathrm{df}=2 / 27, \mathrm{n} . \mathrm{s}$.$) . This result agrees with other studies$ which have shown that differential reinforcement is not necessary for perceptual learning (Pearson \& Hauty, $1.959)$.

Table 1. Average errors for each group at each stage of training*

Errors on same pairs Errors on different pairs

\begin{tabular}{clllllll}
\hline & $\begin{array}{l}\text { Training } \\
\text { Group N Condition }\end{array}$ & $\begin{array}{c}\text { Pre- } \\
\text { Test }\end{array}$ & $\begin{array}{l}\text { Train- } \\
\text { ing }\end{array}$ & $\begin{array}{l}\text { Post- } \\
\text { Test }\end{array}$ & $\begin{array}{l}\text { Pre- } \\
\text { Test }\end{array}$ & ing & Test \\
\hline I & 10 Identification & 2.7 & 1.6 & 2.0 & 0.9 & 1.7 & 1.2 \\
II & 10 Reinforcement & 2.7 & 1.9 & 1.2 & 1.0 & 1.4 & 1.3 \\
III & 10 No information & 2.9 & 2.1 & 1.4 & 1.1 & 1.5 & 1.7 \\
\hline
\end{tabular}

* Errors for training are average per 10 trial block to make training comparable to the pretest and posttest. 
The major evidence of perceptual learning was in the identification of sameness. The overall analysis of variance showed significance on the $S-D$ factor $(F=$ 31.86, df $=1 / 27, \mathrm{p}<.001$ ) and a significant interaction of S-D comparisons with the time (pretest or posttest) when the comparison occurred $(F=21.69, \mathrm{df}=1 / 27$, $p<.001$ ). Same pairs were judged correctly $44 \%$ of the time on the pretest and $70 \%$ on the posttest $(t=4.446$, $p<.001)$. Different pairs decreased slightly in accuracy over time $(t=1.767, p<.10)$.

Table 2 shows the accuracy of judgments for each wine paired with itself (same judgments) or with other wines (different judgments). This table might show if some wines are noticeably "distinctive" as compared to others. ${ }^{2}$ Diana seems more distinct than other wines on the pretest, but the slight initial advantage was quickly erased.

\section{Discussion}

The topic of same-different judgments has been highlighted in a recent paper by Bindra, Williams, \& Wise (1965). They used successive S-D judgments for tones. Most of the errors were made by judging two identical tones to be different, rather than in considering two different tones to be the same. Latencies for judgments of sameness were consistently longer than latencies of different judgments.

That latencies for judgments of sameness are longer is not surprising for complex stimuli. Consider a man trying to judge whether two cards are the same or different when the cards may differ in dimensions of color, form or number of elements. Judgments of difference can be made, on the average, after examining between one and two dimensions. Sameness judgments can never be made until all three dimensions are examined.

Successive judgments, with variable latencies, get into psychophysical problems of "time errors" (Woodworth \& Schlosberg, 1954). Time error research would seem to show that "same" stimuli successively presented are judged as "different" in many sense modalities. A lighter weight is required for a judgment of "equal" (same) after the standard weight is presented (a negative time error). Tones must first be louder and then

Table 2. Accuracy of judgments for each wine (per cent correct) (30 Ss)

\begin{tabular}{lcccccr} 
& \multicolumn{2}{c}{$\begin{array}{c}\text { Same pairs } \\
\text { Wine }\end{array}$} & Pretest & Training & \multicolumn{3}{c}{ Dosttest } & Pretest Training & Posttest \\
\hline Catawba & $40 \%$ & $55 \%$ & $87 \%$ & $83 \%$ & $72 \%$ & $75 \%$ \\
Delaware & $30 \%$ & $53 \%$ & $73 \%$ & $70 \%$ & $62 \%$ & $70 \%$ \\
Diana & $67 \%$ & $60 \%$ & $53 \%$ & $87 \%$ & $73 \%$ & $75 \%$ \\
Niagara & $37 \%$ & $72 \%$ & $70 \%$ & $81 \%$ & $77 \%$ & $71 \%$ \\
Riesling & $50 \%$ & $72 \%$ & $63 \%$ & $78 \%$ & $66 \%$ & $68 \%$ \\
\hline
\end{tabular}

softer than the standard to be judged as the same in loudness as time between presentation of the stimuli is increased. Successive visual stimuli arealso affected for intensity judgments.

Many factors may influence the decision of Sto make a same or a different judgment: "set," motivation, past experience, etc. Consequently, Bindra etal discuss sameness-difference in terms of decision theory.

The task of the $S$ in judging sameness in this experiment was a difficult one. He had to try to match newly discovered dimensions of stimuli thay may have changed in unknown ways (the "time error") from one sip to another. Initially most wine sips tasted different and only through experience was $\mathrm{S}$ able to map out similar dimensions of the stimuli. The perceptual learning task becomes allied to "concept learning. " James wrote many years ago: "(The) sense of sameness is the very keel and backbone of our thinking ... Without the psychological sense of identity, sameness might rain down upon us from the outer world for ever and we be none the wiser" (James, 1890, I, 459-460).

The perceptual learning in this experiment did not seem to depend on any particular training condition; experience by itself was enough. In a longer experiment, or with different training methods, training conditions might be important, but some perceptual learning can apparently take place without any particular training. Sameness-difference as a judgmental task has not been intensively investigated. As Bindra et al point out, 'little is known of the 'sameness-difference' judgment per se." It is a complex task that should be studied further.

\section{References}

Bindra, D., Williams, J. A., \& Wise, J. S. Judgments of sameness and difference: experiments on decision time. Science, 1965 , $150,1625-1627$.

Gibson, E. J. Improvement in perceptual judgments as a function of controlled practice or training. Psychol. Bull., 1953, 50, $401-431$.

Gibson, J. J., \& Gibson, E. J. Perceptual learning: differentiation or enrichment? Psychol. Rev., 1955, 62, 32-41.

James, W. The principles of psychology. New York: Holt, 1890. 2 vols.

Pearson, R. G., \& Hauty, G. T. Adaptive processes determining proprioceptive perception of verticality. J. exp. Psychol., 1959, $57,367-371$.

Woodworth, R. S., \& Schlosberg, H. Experimental psychology. (Rev. ed.) New York: Holt, 1954.

\section{Notes}

1. The Widmer Co. generously donated the wine. Jesse Smith helped conduct the experiment, carried out in 1959, with the cooperation of the students of Psychology 216, Cornell University. 2. One wine used in the 1957 preliminary study, Salem, was not used in this experiment because it was too distinctive. 